\title{
YOU NEED TO FOCUS TO VALIDATE
}

\author{
O. Isaksson ${ }^{1, \otimes}$, C. Eckert ${ }^{2}$, M. Panarotto ${ }^{1}$ and J. Malmqvist ${ }^{1}$ \\ ${ }^{1}$ Chalmers University of Technology, Sweden, ${ }^{2}$ The Open University, United Kingdom \\ $\triangle$ ola.isaksson@chalmers.se
}

\begin{abstract}
Many research students find challenges when validating their research. Especially when they have expectations to contribute to both practice and the research body of knowledge. This paper argues that a key to successful validation of design research lies in the ability to focus on what to validate in advance of how to validate. The paper provide a set of guidelines to support a discussion on how to converge to a claim that actually can be validated. The paper reports on experiences from $\mathrm{PhD}$ level course on validation in design research.
\end{abstract}

Keywords: design research, evaluation, research methodologies and methods

\section{Introduction}

"Focus" and "validate" are probably two of the words that PhD students hear the most and find the hardest to realise in practise. Students start with great enthusiasm, hope and expectations. During the 3 to 5 years of research studies ahead, there is a need to reach research results that can be claimed to contribute to knowledge and often practice. This paper argues that validation of the research is closely linked to the claim made. The claim can be a hypothesis that needs to be falsified or corroborated, a thesis that is argued or the response to research questions. The focus of the research is related to the goal of the research, but includes the lens through which this is addressed thereby including both a theoretical and a methodological stance. Unless research has a clear focus, it is unlikely that it can make a clearly articulated contribution to knowledge. This link between the focus of the research and the validation of the research is missing in other discussions of research validation. The problem addressed in the paper is that industrial problem situations often are too wide and too complex to serve directly as a research gap where specific knowledge contribution claims can be made.

This paper revisits central concepts used in design research. The intent is to provide a useful set of central concepts for planning and evaluating research studies; and offer a pragmatic discussion for research supervisors and students by proposing practical steps that students can take to help them to focus their research and validate their work against clearly articulated research claims.

Validation is of course not only an issue for PhD students, but for all research. Based on a sample of 71 paper published in Research in Engineering Design, Barth et al. (2011) have shown that $37 \%$ of the articles had no validation at all and $46 \%$ had no industrial application. While the exact figures will have changed in the meantime, they illustrate the wider challenge in the community with validating engineering design research.

How engineering design research can be validated in practise depends on the nature of the research that is being validated. Engineering design research brings together different research perspectives, sometimes in 
a single piece of work and certainly in the range of the research that is carried out. Some research draws heavily on engineering science, which relies largely on the physical sciences and it therefore carried out through experimental and analytical research. Other research come from a social science tradition where the way humans think or interact with each other or technology is studied. Much of this research is based on observation or action research, while other research is purely theoretical and derived from a humanity tradition of the well-developed argument. Often, research projects, in particular thesis projects involve elements of all three, as the students need to understand the context of the problems, they are addressing including the human agents in it, but also develop design solutions, tools and methods in an engineering science tradition. This blend of disciplines is a challenge, as most students start their engineering design $\mathrm{PhD}$ with a skill set from either engineering science or social science and therefore only have a partial understanding of the research methods required from their preceding education.

Fundamentally research is about making a contribution to knowledge and increasing our collective understanding by advancing the debates and current understanding that surround that particular topic of research. In addition, research often makes, and more importantly is required to make, a direct contribution to practice for example by addressing a problem in a case study company. However, the contribution to practice and the contribution to knowledge are not the same. A practical contribution can be in the application of existing knowledge, that is not known or previously used in the practical, often industrial, context. Much design research is carried out in conjunction with industry or directly for industry. In this case it is also necessary to validate the contribution the research is making to industry and the scope of the contribution. Are the results relevant to a particular company, an industry sector or industry at large? Validation is also critical to industry, who is often the "customer" of the research, in two fundamental ways. Industry needs to be able to trust the validation of design research before they can be confident to apply the outcomes of the research in their own context. Moreover, when industry experts develop their own tools and methods, they need to validate them for internal use or before sharing best practise across companies.

The paper begins by briefly reviewing the literate on validation in design in section 2 before explaining the methodology we used in section 3. Section 4 summarises observations from a $\mathrm{PhD}$ course on validation of design research. Section 5 introduces a set of concepts and discusses how research can be focussed. It includes a set of diagrams that show the process of focussing research and indicate the orders of magnitude of relevant research. Section 6 concludes the paper.

\section{Literature}

Validation is at the heart of any academic fields because it determines the scientific rigor of the field. Validation is often talked about in conjunction with verification, which are colloquially often described as the distinction between "doing it right" - verification - and "doing the right thing" validation. The ISO describes both verification and validation as processes, and provides a general and useful start with the following definitions (ISO, 2015) with the notable difference that the "intended use" is associated to "validation".

\section{Verification - "confirmation, through the provision of objective evidence, that specified requirements have been fulfilled " \\ Validation - "confirmation, through the provision of objective evidence, that the requirements for a specific intended use or application have been fulfilled"}

The topic of validation and verification is of central important for product development as well. The modelling and simulation community is concerned with the validity of models. According to the American Institute of Aeronautics and Astronautics, model validation is "the process of determining the degree to which a model is an accurate representation of the real world from the perspective of the intended uses of the model" (AIAA, 1998), and a similar view is provided by Sargent (2013). Validation also been addressed by researchers in the engineering design research. According to Blessing and Chakrabarti (2009) "design research has two, related objectives: the formulation and validation of models and theories about the phenomenon of design, and the development and validation of support founded on these models and theories, in order to improve design practice, including education, and its outcomes". 
One common point of agreement in literature is that in research claims or hypotheses need to be validated (Robson, 2002). In this context, Cantamessa (2003) analysed past ICED conferences and identified the following categories of research by their primary objectives:

- Empirical research: analysis of real-world design process and practice,

- Experimental research: study of design process in controlled environment.

- Development of new tools: development of tools to support design process or activity.

- Implementation studies: study of deployment of NT to real-world situations

- Other: study dedicated to theory and education

At the time nearly $50 \%$ of the research was dedicated to the development of tools or methods. In practice most research is a combination of these. $\mathrm{PhD}$ researchers in particular often have to cover several of these aspects and therefore need to articulate which contributions they are making to each of these. These different types of research also call for different validation methods. Barth et al. (2011) identified the following types of validation in their analysis of published papers: Application, Comparison, Focus groups, Questionnaire, Simulation, Statistical analysis, which combine with empirical and analytical methods. Le Dain et al. (2013) pick up on this distinction between empirical research and what called simulation research (essentially the last two categories of Barth et al. (2011)) and look at criteria for validation. They propose the dimensions shown in Table 1.

Table 1. Validity criteria according to Le Dain et al. (2013)

\begin{tabular}{|l|c|r|}
\hline Dimension & Simulation research & Empirical research \\
\hline Truth value & Internal validity & Credibility \\
\hline \multirow{2}{*}{ Applicability } & External validity & Transferability \\
\cline { 2 - 3 } & Generalisation falsification & Analytical generalisation \\
\hline Consistency & Reliability & Dependability \\
\hline \multirow{2}{*}{ Neutrality } & Objectivity & Confirmability \\
\cline { 2 - 3 } & Construct validity & \\
\hline
\end{tabular}

As design research draws on multiple disciplines the validation methods also can come from many different areas of research and needs to be up to the standards of the fields it draws from (Eckert et al., 2003). As a multidisciplinary field design research can also learn from other multidisciplinary fields with more developed practises. Frey and Dym (2006) point out that design research can learn from medicine and argue that analogies can be found. Controlled field experiments can be seen as the equivalent of clinical trials, studies of industrial practice as material experiments and lab experiments as the equivalent of in vitro experiments, while detailed simulations can be seen as analogous to animal models. However, in design the product being designed has a profound effect on the process through which it is being designed and the numbers of design case studies one can carry out are limited not only by the resources that are required, but also by the availability of potential case studies, for example there is only a very small number of companies building jet engines.

Given this centrality of validation and verification in research, researchers have concentrated on what approach is suitable for which kind of research, what evaluation criteria might be suitable, what elements of the research need to be validated and when this validation should take place. For example, (Guba and Lincoln, 1989) and Buur (1990) suggests two kinds of methods for assessing the validity of a design theory, model, or tool:

- Logical verification: this process emphasizes consistency (i.e. there are no internal conflicts between individual elements (e.g., axioms) of the theory) and completeness (i.e. all relevant phenomena observed previously can be explained or rejected by the theory, such as observations from literature, industrial experience etc.). In this process, researchers need to look for wellestablished and successful methods in accordance to theory, as well as cases (i.e., particular design projects) and specific design problems that can be explained through the theory.

- Verification by acceptance: this process includes experienced designers to accept statements of the theory (axioms, theorems) and models and methods derived from the theory. 
For case study research (Yin, 2014) a well-thought-out strategy and instrumentation for data collection, analysis, interpretation, and composition is crucial to provide trustworthy results. This is often referred to as construct validity. This may involve using multiple data sources, analysing different data sources simultaneously, and collaborating with other researchers, constructing chains of evidence (for instance by your model/tool reflecting reality), and preliminary results reviewed by key informants. Pedersen et al. (2000) proposed the validation square consisting of four quadrants, which combine the internal consistence of the research and its application to a target context along the following dimensions: 1 . Theoretical structural validity. 2. Empirical structural validity. 3. Empirical performance validity, and 4. Theoretical performance validity. Eckert et al. (2003) divided design validation by the phases that design research goes through from empirical studies and understanding the problem, to theory development, to the development of tools and methods and to their introduction. They suggest that the findings of each of these phases needs to be evaluated separately according to the disciplinary standards of the discipline they draw on. This advocates to validate the understanding of the problem separately from the approach to address it, and also makes the theory or model building component explicit. This enables the researcher to identify clearly both the scope of their research and the occurrence of potential failures. The design research methodology by Blessing and Chakrabarti (2009) bundles validation across stages of the research and advocate to validate the entire research through the improvements observed during a second case study.

Despite the centrality given to validation and verification in literature on design research, literature seem to agree that the ways of validating design research are not clearly defined, which leads to inefficiencies of the design research process. Paraphrasing (Blessing and Chakrabarti, 2009, p.8):"even though many research projects are successful, this is often at the expense of an inefficient research process". Many reasons for these difficulties exist (Blessing and Chakrabarti, 2009, p.7), but one of the main reasons lies in design itself as an object of investigation, since "many proposed designs will never be realised and that it is often infeasible to follow the realised designs through their complete life cycles" (Seepersad et al., 2006). One of the central issues is also the limited attention that researchers put on the formulation of the claims that they making (Shaw, 2003; Frey and Dym, 2006), which is the problem addressed in this paper.

\section{Methodology}

This research draws on the prior work on validation and discusses how students can understand exactly what claims that they are making in their research and therefore what they need to validate. The insights presented in this paper were developed as part of teaching a course in research methodology to research students at Chalmers in 2018. The materials presented in section 5 have been given subsequently to other PhD students to help them to frame up their own research. The paper does not present the findings of a conventional research study, but an attempt of the authors to share their experiences and ignite a discussion in the research community on how to raise the standards of research in our field, by helping students to clearly focus their research and thereby articulate their contribution.

The overall learning objective was given to the research students in the following brief: “... you shall be able to understand, reflect, assess and argue for topics and factors impacting the validity of design research studies. Using your own research context as an example, you shall be able to systematically problematize and formulate questions and arguments that clarifies the validity of design research, in particular when applied in industrial settings".

The course consisted of three stages spread over a four-month period. The students were introduced to the concept of validation and presented their own work to the group. They were then asked to prepare a validation plan for their research. This was presented to the group as a power point presentation, where the students and instructors had the opportunity to question the students about their research. As a final step the students produced a refined validation plan. The course assignment was the incremental development of a validation plan, that could be used as a draft for their thesis.

A group of 6 students took part throughout the course at different stages of their Swedish 5 year $\mathrm{PhD}$ program. Two students had completed their first year, one student his second year and the others were about to finish their PhD studies. The students were all working at the Product Development Division 
at Chalmers, with research projects in tight collaboration with industrial partners. As such, they all had to relate to wider industrial problems in parallel to their specific research tasks. Their research challenge and starting point is usually closely related to a practical industrial problem. Typical problems are related to how a certain (novel) technology impacts the robustness of an end product, or a manufacturing process. Others were expected to develop a novel and better modelling and simulation tool to predict and evaluate specific phenomena in production already during design. In general, they all required empirical studies to understand practical situations and effects, as well as to propose design approaches to better deal with the situations and phenomena studied.

\section{Observation from the course}

All the student worked closely with industry, who also partially sponsored their $\mathrm{PhDs}$ and provided industrial problems. The initial research areas where defined broadly, such as "improving the ability in industry to predict \{some phenomena\}", or "To enable \{certain aspect\} to be included in the early phase decision making in product development".

Their close relation to industrial partners gave them an in-depth exposure to the industry practise, but also drew them into the specific problems and needs of their partner companies. The challenge that they were faced with was defining exactly the contribution both to knowledge and to the industry partner they wanted to make. Their industry partner would have been happy if the students addressed their problems without demanding any particularly novel and generalisable work. Improving decision making in industry, as targeted in several cases, requires deep engagement with industrial situations, interacting with specific software, proprietary data, testing procedure, change management procedures and so forth. The industrial problems were multi-faceted and required deep knowledge of the company. Several relevant scientific problems can be found within most industrial problems. They require the students to define a controllable and focused research problem.

This leaves the students with the challenge to articulate the contribution to knowledge they would like to make and more importantly they can make. Especially for the new students some of the challenge lay in identifying what is background knowledge that they draw on and what body of knowledge they are making a contribution to. For example, they all worked on complex systems of some kind, but needed to understand that they were unlikely to make a contribution to the theory of complexity. Alternatively, while working on heat simulation models to improve decision making, the validation of the simulation tools as design tools was found more difficult than to validate how well they predicted the targeted physics-based phenomena. The task to formulate a validation plan was for most student tied up with planning their entire research and was found to be difficult but useful and gave rise to many questions. In order to plan their research, they needed to go through the process of finding a focus for the research, as we describe in the following section. Even long after the course had ended, and the students were in their thesis writing process, they reflected to the authors of this paper that they "would have appreciated the course even more now". Theoretically, the concepts discussed were not difficult to understand but the effort to apply them to their own research was not perceived as straightforward.

\section{Finding a focussed claim to validate the research}

Before researchers can think about how to validate their research, they needed to understand what to validate. This required finding the focus of their work and articulating the contribution they want to make. It is well recognised that design research in practice is rarely a linear and straightforward process. Sometimes the research task is already formulated at the beginning for example in terms of developing an improved algorithm that that addresses a particular phenomenon. Other $\mathrm{PhD}$ students start their research journey with industrial and societal problems, that are poorly defined form a scientific perspective. They are provided with problem specifications based on symptoms where underlying reasons typically are multi-facetted. For example, they might be told that certain design processes deliver unsatisfactory results and lead to cost overruns since additional resources, actions and loop backs are needed. The industry stakeholder or the supervisors may have a preconceived view on where the problem reside and how to address it - e.g. through introducing new resources, tools or work procedures. 


\subsection{Focusing the research scope to validate}

The students have to find their own research problem by focusing their work. As an example, while a heat simulation problem can seem tightly specified, the question remains whether the new simulation models is a contribution to the specific design problem, the modelling of welding to or simulation in general. This scope needs to be established to validate the claim of "I have developed a more effective and efficient method for X".

In another case the student is given a practical problem in the design process of a company and needs to unpack the different causal connections hidden in the problem situation. This might be a focus and contribution in its own right, or they can drill down to a specific issue, such as trust amongst team members and aim to make to contribution to that. Even once the problem has been narrowed down in scope, the students need to develop a claim - or main thesis they wish to argue. For example "a more transparent workflow can improve trust" and verify the claim and validate their proposed solution, e.g., a data visualisation system. The iterative cycle of narrowing down to the research claim is shown in Figure 1. This is a simplified version of the Sargent (2013) model of design validation. It also shows the inherent similarity between design research and design problems, where an analysissynthesis-evaluation cycle (Asimov, 1962) is required to identify the underlying problem that can be addressed by the design within the means and abilities of the designer.

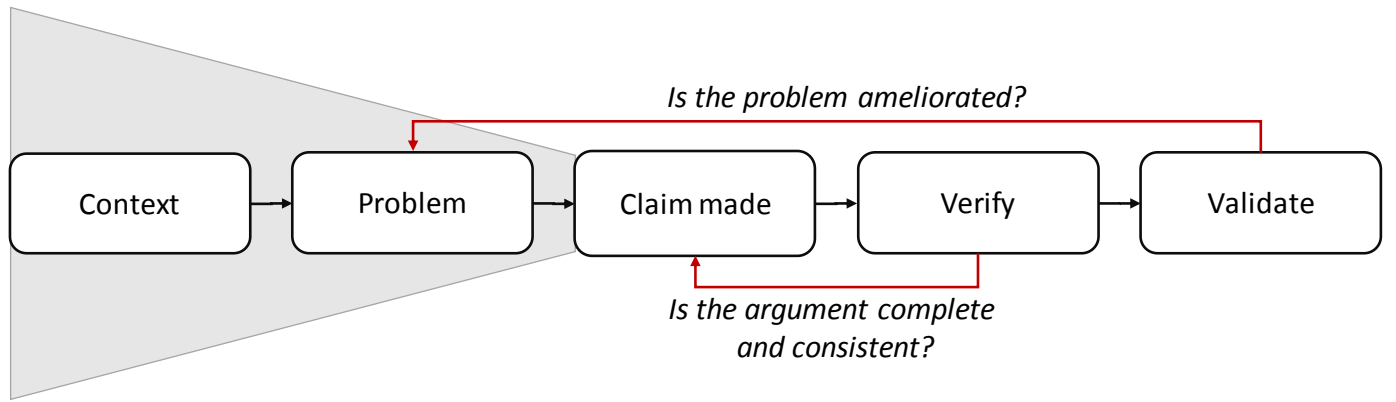

Figure 1. Focusing to enable verification and validation of the problem

\subsection{Finding the research focus in an industrial problem}

Typically, industry has a need or practical problem related the practical context, which leave to the researcher to identify the relevant literature. Principally, the relation between the practical problem and a research problem is illustrated in Figure 2. It is often possible to find a large number of research problems within the practical problem. Therefore, there is a need to identify the most relevant literature that help focusing research to identify knowledge gaps. This is typically an iterative process as good knowledge within a domain is necessary to judge what is relevant.

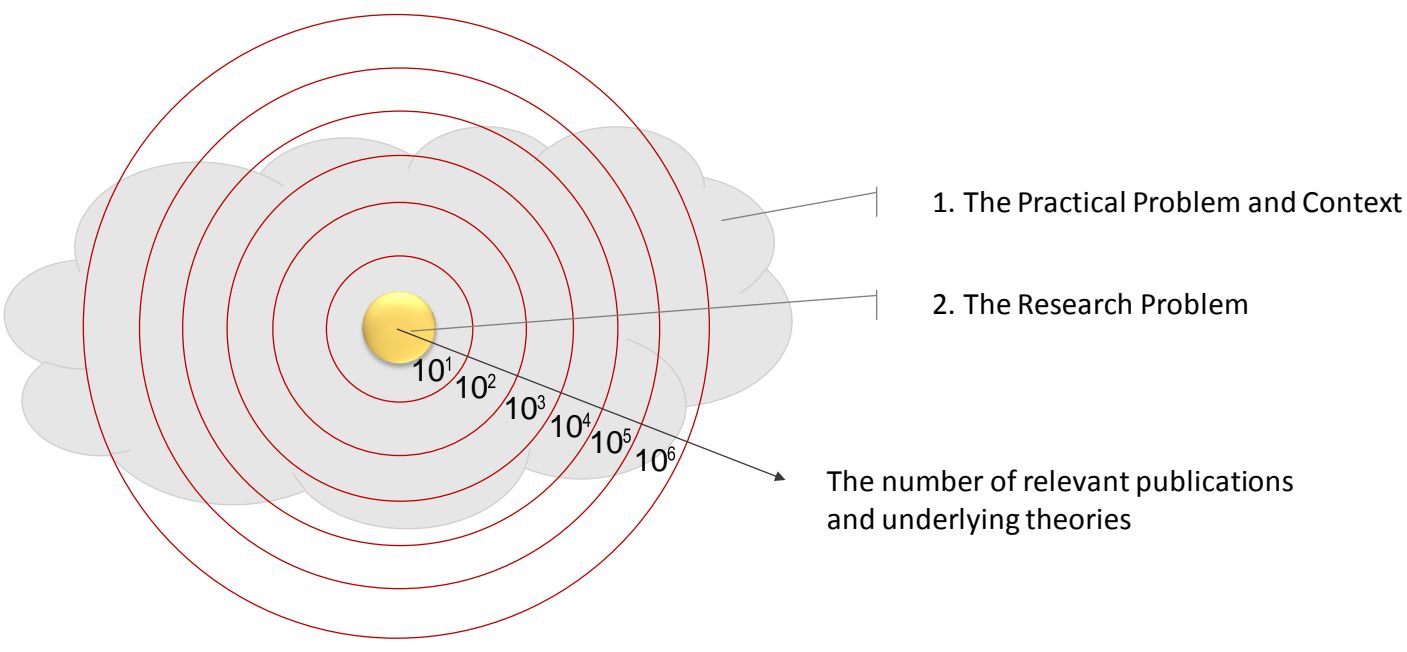

Figure 2. The relation between the applied problem, in a context, and the research problem 
An important aspect is that the relevant literature to position against needs to be clear and covered. Often, the research area can be addressed from the perspectives of several knowledge domains (e.g. Knowledge Management, Systems Engineering, Biology, Management, Decision theory etc). Therefore, it is relevant to frame your research vs. several knowledge domains. It is further necessary to articulate your own view (or "angle") to the problem which only covers a subset of available literature, since each knowledge domain is likely to have a unique terminology.

\subsection{Focussing the research contribution}

There is a need to identify and map what knowledge domains are applicable to the specific problem and position your research view on the problem. Building on ARC diagrams (Area of Relevance and Contribution) used by Blessing and Chakrabarti (2009), Figure 3 extents Figure 2 to illustrate how to systematically position the research to enable a contribution. As illustrated, knowledge domains intersect, and a researcher need to choose an approach -"an angle" to the problem. This view influence what research methods and tools that are appropriate.

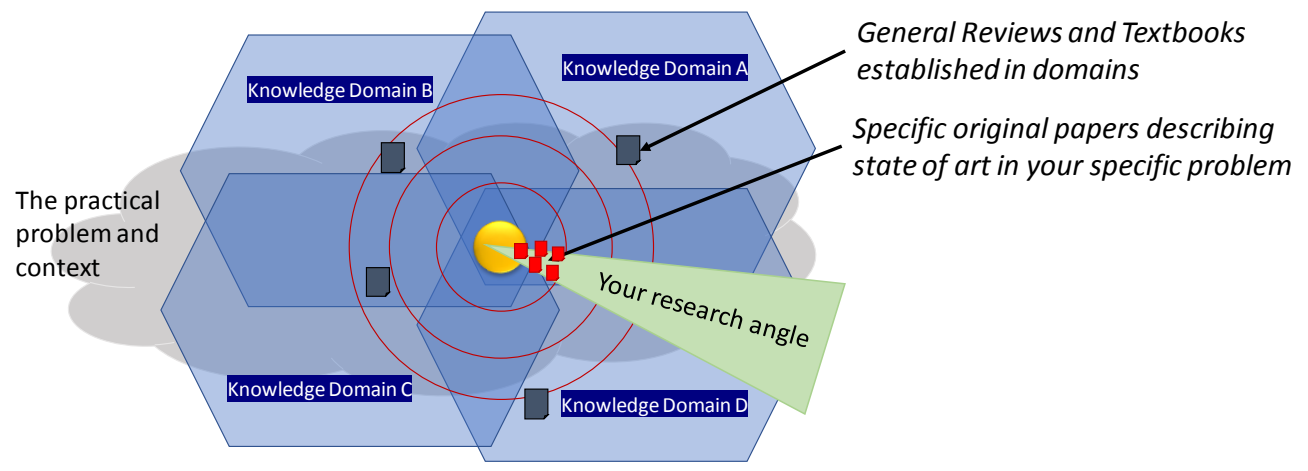

Figure 3. Framing your research vs knowledge domains and picking your angle

To find out the different knowledge domains relevant to the problem, good review publications and established books in the field are often helpful, but to understand the state of art and research gaps more precisely, there is a need to identify how others have addressed the same or similar problems. It is not sufficient to rely on general and broad knowledge reports for such analysis. To make a knowledge contribution it is necessary to carefully identify and review the specific literature most relevant for the specific problem and define how you can contribute here to the body of knowledge.

\subsection{Journey to validation}

Figure 4 illustrate the research journey to make a validated contribution to knowledge as well as a contribution to practise. Most design research is carried in a practical context, in which case studies, examples or empirical studies are located, as well as a research context, where the group or supervisors have a track record of working on a particular theme, or using a particular method. This often brings a specific (often unarticulated) theoretical lens through which they look at practical problems. Within these research themes the student needs to identify a research gap where they can make a contribution to knowledge. A student can usually not assume to address the identified research gap in its entirety, rather they have to find a focus for their own research. This focus often come from the practical problem they want to address. In practise this might be provided by partner companies. They might work on a specific component or process, but usually the contribution needs to be wider than resolving a specific problem. The focus might also come from the student's general interest, academic background and interest. Some students also have a strong methodological preference.

Within a particular research focus the student can identify research questions, which they personally can address within the given time of their thesis. Many students also formulate a hypothesis from which they derive the research questions. The issue of time is important as the defines the parameter of ambition. Sometimes $\mathrm{PhD}$ thesis projects are set up by the supervisors with a particular hypothesis or research objective in mind. In experimental disciplines a clear hypothesis is required to conduct the empirical part of the research. In other theses a hypothesis only emerges as the research progresses and 
causal connections become clearer. PhD thesis research often include all the steps shown in Figure 4, but this emphasis varies and the balance between the research side and practise side differ. Note that the emphasis can also shift throughout a thesis project, as great theoretical contributions have arisen from practical problems and vice versa. Validation needs to be part of both the contribution to knowledge and the contribution to practise. As Figure 4 indicates once research hypotheses are defined, there is an iterative loop between the research questions, the research and the results as a process of verification. The practical work is typically worked out in practise and refined through application. Every thesis has a unique balance between contribution to knowledge and contribution to practice. Any research student needs to establish this balance and ensure that this balance is in compliant with expectations of their academic and industrial context.

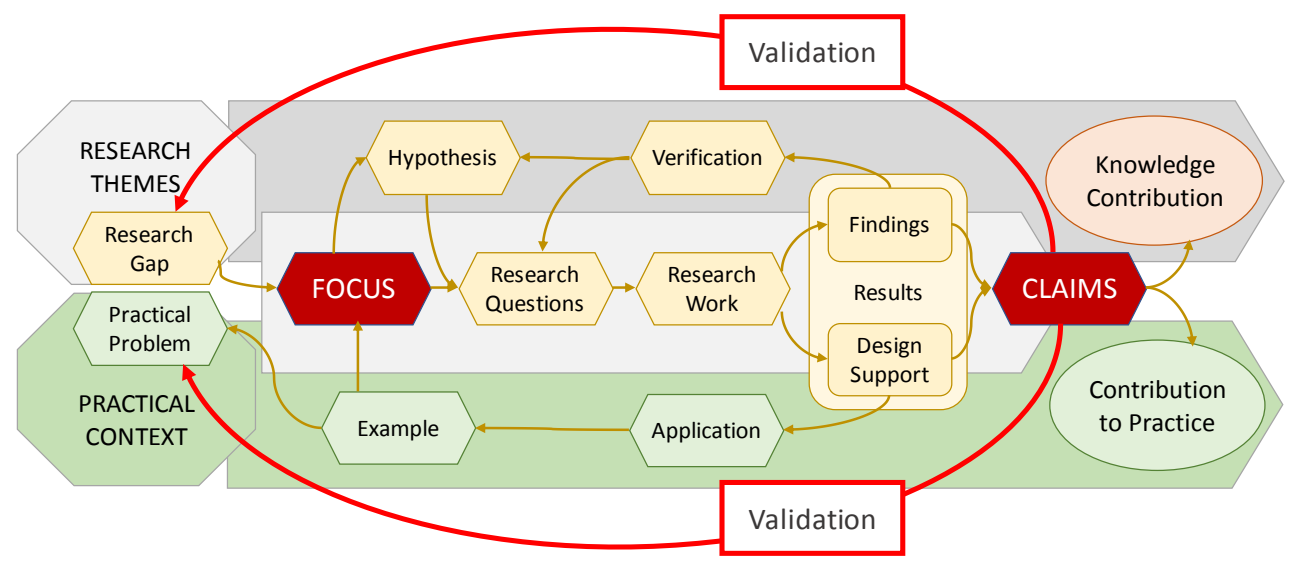

Figure 4. Journey to validation

The research questions usually guide the research; however, research can also be opportunistic and pursue issues outside of the scope of the original questions. Table 2 gives a definition of some of the key terms shared informally with the students during the $\mathrm{PhD}$ course.

Table 2. Terms

\begin{tabular}{|c|c|c|}
\hline Term & Explanation & Illustrative example \\
\hline Practical Context & $\begin{array}{l}\text { The situation in which something } \\
\text { occurs and that can help explain it }\end{array}$ & $\begin{array}{r}\text { In early truck design decisions on variants } \\
\text { offered are made. }\end{array}$ \\
\hline $\begin{array}{l}\text { Practical } \\
\text { problem }\end{array}$ & $\begin{array}{l}\text { The problem as described in the } \\
\text { practical context. }\end{array}$ & $\begin{array}{r}\text { "We don't configure our products well enough } \\
\text { to meet customer needs" }\end{array}$ \\
\hline Example & $\begin{array}{l}\text { A concrete/specific instance of the } \\
\text { practical problem }\end{array}$ & $\begin{array}{l}\text { "Discrete platform options lead to a too small } \\
\text { tank for medium trucks in the last platform" }\end{array}$ \\
\hline Problem & $\begin{array}{l}\text { What you specifically want to achieve } \\
\text { and the barrier to it }\end{array}$ & $\begin{array}{l}\text { "Dependencies models between design } \\
\text { elements objects don't support trade-offs." }\end{array}$ \\
\hline Research Gap & $\begin{array}{l}\text { What nobody has done so far in } \\
\text { addressing the problem }\end{array}$ & $\begin{array}{l}\text { "No visualisations for concepts mixing } \\
\text { hardware, software and services exist." }\end{array}$ \\
\hline Hypothesis & $\begin{array}{l}\text { A specific claim that you set up to } \\
\text { prove or falsify. }\end{array}$ & $\begin{array}{l}\text { "A DSM with energy, information and } \\
\text { material allows systematic exploration of } \\
\text { design alternatives during conceptual design." }\end{array}$ \\
\hline $\begin{array}{l}\text { Research } \\
\text { Questions }\end{array}$ & $\begin{array}{l}\text { Questions whose answers address the } \\
\text { problems and be tested }\end{array}$ & "What are the ..."?", "How can ...?" \\
\hline Claim & $\begin{array}{l}\text { A clear expression of the contributions } \\
\text { the research makes. }\end{array}$ & $\begin{array}{l}\text { "This tool will improve work practice..." } \\
\text { "X can be understood based on the results" }\end{array}$ \\
\hline $\begin{array}{l}\text { Contribution to } \\
\text { knowledge }\end{array}$ & $\begin{array}{l}\text { The validated claims are contributions } \\
\text { to the body of knowledge }\end{array}$ & $\begin{array}{r}\text { "A diagrammatic representations aids } \\
\text { designers to access knowledge outside the } \\
\text { immediate design task." }\end{array}$ \\
\hline $\begin{array}{l}\text { Contribution to } \\
\text { practice }\end{array}$ & $\begin{array}{l}\text { The validated claims as to how they } \\
\text { contribute to practice. }\end{array}$ & A problem resolved in its practical context. \\
\hline
\end{tabular}


In each thesis many aspects of the research cover familiar ground and will not necessarily be contributions to knowledge or contributions to practise. Therefore, the students need to identify carefully what constitutes a contribution. A contribution needs to be novel and to some extend generalisable or transferable. At the same time, it needs to be specific enough to be possible to validate. Some contributions can be detailed and specific, while other make more general points. The thesis needs to assess to which extent the knowledge gap has been addressed and to whether the contribution has been useful to industrial practise.

This duality of the contribution is a frequent source of misunderstanding. Many students carry out research that is very helpful to industrial partners, who are happy with the results. This does not necessarily imply a contribution to scientific knowledge.

Once the results have been verified the potential claims can be formulated. To what degree they are valid need to be investigated since if not, you at best corroborate. A successful outcome for the thesis in the specific application case, is not the same as a validation. Rather it is necessary to find out whether the results actually address the practical problem before contribution to practice can be claimed. In most industrial situations, a complete validation is nearly impossible, since the relevance would require extensive and long-term studies. In practice, especially for a $\mathrm{PhD}$ thesis, the validation exercise cannot be made until very late in the process giving little time to act. It is necessary to balance the claims made with the validation conducted.

Equally, to claim contribution to knowledge there is a need to position the result and proposed claim in the research gap. This is in some way easier, since the state of art is commonly accepted as what has been published and assessed before.

For when validating practical and knowledge contributions (claims) it is important to be as precise as possible, in order to match the claim with what is possible to validate. The interesting generalisations and wider implications may still be discussed and possibly suggested as relevant extensions for further work. This means also that what is scientifically claimed and validated, may not be what is most valuable for the practical situation.

\section{Concluding discussion}

The core message of the paper is that a clear focus of research is critical. One reason is the dual nature of contribution; to knowledge and to practice. Both require validation but of different reasons and by different means. Contribution to practice is validated in the targeted practical context and issues of validity often are associated with questions on how generalisable the results are. Knowledge contribution is validated on the degree of novelty, compliance (or not) with what is found in scientific literature. Sometimes these perspectives are difficult to separate out, as the results are generated in the same studies.

Another reason is the nature of design research which often touch on different domains. Engineering Design is a mix of engineering and social disciplines, where accepted means and approaches to validation may differ. The paper does not report on a conventional research study, rather it shares insights and models developed and used in a $\mathrm{PhD}$ course on validation in design research, where the students experienced that the topic of validation is easier said than done in engineering design research. More advanced PhD students found the discussion and visualizations used in the paper useful to structure and present their own research. While students at the beginning found it difficult to accept the need to focus and accept the limitations of what a $\mathrm{PhD}$ can achieve, the analysis helped us as supervisors to structure our discussions with the students. These principles also apply to other forms of research activities, such as research activities, projects or publication processes.

\section{References}

AIAA (1998), Guide for the verification and validation of computational fluid dynamics simulations, American Institute of Aeronautics and Astronautics AIAA G-077-1998.

Asimov, M. (1962), Introduction to Design, Prentice-Hall, Englewood Cliffs, NJ, 1962.

Barth, A., Caillaud, E. and Rose, B. (2011), "How to validate research in engineering design?", In DS 68-2: Proceedings of the 18th International Conference on Engineering Design (ICED 11).

Blessing, L.T. and Chakrabarti, A. (2009), DRM, a Design Research Methodology, Springer, London, 2009. 
Buur, J. (1990), A Theoretical Approach to Mechatronics Design, [Ph.D. Thesis], Institute for Engineering Design, Technical University of Denmark, Lyngby, Denmark.

Cantamessa, M. (2003), “An Empirical Perspective Upon Design Research”, Journal of Engineering Design, Vol. 14 No. 1, pp. 1-15. https://doi.org/10.1080/0954482031000078126

Eckert, C.M., Clarkson P.J. and Stacey M.K. (2003). "The Spiral of Applied Research: A Methodological View on Integrated Design Research", ICED03: 14th International Conference on Engineering Design.

Frey, D.D. and Dym, C.L. (2006). "Validation of design methods: lessons from medicine", Research in Engineering Design, Vol. 17 No. 1, pp. 45-57. https://doi.org/10.1007/s00163-006-0016-4

Guba, E.G. and Lincoln, Y.S. (1989), Fourth Generation Evaluation, Sage Publications, Newbury Park, CA, USA.

ISO (2015), "ISO 9000:2015 Quality management systems - Fundamentals and vocabulary", Accessible via https://www.iso.org/

Le Dain, M.A., Blanco, E. and Summers, J.D. (2013), "Assessing design research quality: investigating verification and validation criteria", In DS 75-2: Proceedings of the 19th International Conference on Engineering Design (ICED13).

Shaw, M. (2003, May), "Writing good software engineering research papers", In 25th International Conference on Software Engineering, 2003. Proceedings, IEEE, pp. 726-736.

Robson, C. (2002), Real world research, Second Edition, Blackwell Publishing, Oxford.

Pedersen K. et al. (2000), "Validating design methods and research: the validation square", DETC2000/DTM14579. In: Proceedings of the ASME design engineering technical conference, Baltimore, https://doi.org/10.1115/1.802469.ch25

Sargent, R.G. (2013), "Verification and validation of simulation models", Journal of Simulation, Vol. 7 No. 1 , pp. 12-24. https://doi.org/10.1057/jos.2012.20

Seepersad C.C. et al. (2006), “The Validation Square: How does one verify and validate design methods?", In: Chen W. et al. (Eds.) Decision Making in Engineering Design, ASME Press, New York, pp. 303-314.

Yin, R.K. (2014), Case Study Research: Design and Methods, 5th Edition, Sage Publications, Thousand Oaks, CA, USA. 